\title{
A RANDOMIZED TRIAL OF SURGERY WITH AND WITHOUT CHEMOTHERAPY FOR LOCALIZED SQUAMOUS CARCINOMA OF THE THORACIC ESOPHAGUS: THE JAPAN CLINICAL ONCOLOGY GROUP STUDY
}

\author{
Nobutoshi Ando, MD, FACS ${ }^{\mathrm{a}}$ \\ Toshifumi lizuka, $\mathrm{MD}^{\mathrm{b}}$ \\ Teruo Kakegawa, MD, FACS \\ Kaichi Isono, MD, FACS ${ }^{d}$ \\ Hiroshi Watanabe, MD \\ Hiroko Ide, $\mathrm{MD}^{\mathrm{f}}$ \\ Otsuo Tanaka, $\mathrm{MD}^{\mathrm{g}}$ \\ Masayuki Shinoda, $\mathrm{MD}^{\mathrm{h}}$ \\ Wataru Takiyama, MD ${ }^{i}$ \\ Masaki Arimori, $\mathrm{MD}^{\mathrm{j}}$ \\ Kaoru Ishida, $\mathrm{MD}^{\mathrm{k}}$ \\ Shoichiro Tsugane, $\mathrm{MD}^{\mathrm{l}}$
}

\begin{abstract}
Objective: To determine whether postoperative adjuvant chemotherapy confers a survival benefit on patients with esophageal squamous cell carcinoma undergoing radical surgery, we undertook a cooperative, prospective randomized controlled trial. Methods: A total of 205 patients underwent transthoracic esophagectomy with lymphadenectomy at eleven institutions between December 1988 and July 1991. These patients were prospectively randomized into two groups (100 patients underwent surgery alone and 105 patients had additional two courses of combination chemotherapy with cisplatin $\left(70 \mathrm{mg} / \mathrm{m}^{2}\right)$ and vindesine $\left(3 \mathrm{mg} / \mathrm{m}^{2}\right)$. The two groups did not differ with respect to sex, age, location of tumor, and distributions of pT, pN, pM, or p stage. Results: The 5-year survival was $44.9 \%$ in the surgery alone group and $48.1 \%$ in the surgery plus chemotherapy group. The relative risk was estimated to be 0.89 (95\% confidence interval, 0.61 to 1.31) in the surgery plus chemotherapy group compared with the surgery alone group. No significant differences in survival were detected between the two groups, even with lymph node stratification. Conclusion: Postoperative adjuvant chemotherapy with cisplatin and vindesine has no additive effect on survival in patients with esophageal cancer compared with surgery alone. (J Thorac Cardiovasc Surg 1997;114:205-9)
\end{abstract}

Cince 1978, the Japan Esophageal Oncology Group (JEOG), a subgroup of the Japan Clinical Oncology Group (JCOG), has developed adjuvant

From the Department of Surgery, School of Medicine, Keio University, Tokyo ${ }^{\mathrm{a}}$; National Oji Hospital, Tokyo ${ }^{\mathrm{b}}$; Department of Surgery, Faculty of Medicine, Kurume University, Kurume $^{\text {c }}$; Department of Surgery, Faculty of Medicine, Chiba University, Chiba ${ }^{\mathrm{d}}$; Department of Surgery, National Cancer Center Hospital, Tokyo ${ }^{\mathrm{e}}$; Department of Surgery, Tokyo Women's Medical College, Tokyo ${ }^{\mathrm{f}}$; Department of Surgery, Faculty of Medicine, Niigata University, Niigata ${ }^{\mathrm{g}}$; Department of Thoracic Surgery, Aichi Cancer Center Hospital, Nagoya $^{\text {h}}$; Department of Surgery, National Shikoku Cancer Center Hospital, Matsuyamai; Department of Surgery, National Tokyo Second Hospital, Tokyo'; Department of Surgery, Iwate Medical College, Morioka ${ }^{\mathrm{k}}$; Epidemiology and Biostatistics Division, National Cancer Center Research Institute, East, Chiba, Japan.'

Supported by a Grant-in-Aid for Cancer Research from the Ministry of Health and Welfare of Japan.

Received for publication August 12, 1996; revisions requested Oct. 7, 1996; revisions received Nov. 6, 1996; accepted for publication Jan. 22, 1997.

Address for reprints: Nobutoshi Ando, MD, Department of Surgery, School of Medicine, Keio University, 35, Shinanomachi, Shinjukuku, Tokyo, 160 Japan.

Copyright (C) 1997 by Mosby-Year Book, Inc.

0022-5223/97\$5.00+0 $\mathbf{1 2 / 1 / 8 0 5 4 8}$ therapeutic modalities for esophageal cancer using randomized controlled trials. ${ }^{1,2}$ These studies have shown an improvement in survival that can be attributed to recent advances in esophageal cancer surgery, ${ }^{2}$ in particular cervical-upper mediastinal lymphadenectomy. ${ }^{3}$ This site had been previously identified as the most frequent site of cancer recurrence. Thus in Japan a transthoracic esophagectomy with extensive lymphadenectomy is now regarded as the standard treatment for patients with cancer of the thoracic esophagus.

Adjuvant chemotherapy for esophageal cancer, however, remains investigational. ${ }^{4,5}$ This study was designed to determine whether postoperative adjuvant chemotherapy confers a survival benefit on patients undergoing a transthoracic esophagectomy with lymphadenectomy for cancer of the thoracic esophagus. Surgery alone was compared with postoperative adjuvant chemotherapy in a multicenter trial.

\section{Patients and methods}

The study was composed of patients who were scheduled to undergo transthoracic curative resection of an esophageal tumor including complete removal of the primary lesion and dissection of the regional and distant 
Table I. Characteristics of eligible patients

\begin{tabular}{lcc}
\hline \multicolumn{1}{c}{ Characteristic } & $\begin{array}{c}\text { Group A: } \\
\text { Surgery alone }\end{array}$ & $\begin{array}{c}\text { Group B: } \\
\text { Surgery }+C T\end{array}$ \\
\hline Entered & 100 & 105 \\
Eligible & 100 & 105 \\
Sex & & \\
$\quad$ Male & 92 & 90 \\
Female & 8 & 15 \\
Age (yr) & $39-75$ & $40-75$ \\
$\quad$ Range & $59.8(8.3)$ & $60.4(9.6)$ \\
Mean (SD) & & \\
No. of CT courses & 100 & 3 \\
0 & & 14 \\
1 & & 88 \\
2 & &
\end{tabular}

$C T$, Chemotherapy; $S D$, standard deviation.

lymph nodes, with esophagogastric or esophagocolic anastomosis in the neck. The regional lymphadenectomy included not only the mediastinal but also the perigastric nodes. The distant lymphadenectomy included cervical or celiac nodes, or both.

These patients were prospectively randomized into two groups: surgery alone (group A) and surgery plus postoperative chemotherapy (group B). Selection was performed by block randomization using the number of patients as the blocking factor within 2 months of the operation. In group B, cisplatin $\left(70 \mathrm{mg} / \mathrm{m}^{2}\right)$ was given by slow drip infusion and vindesine $\left(3 \mathrm{mg} / \mathrm{m}^{2}\right)$ was given by intravenous bolus infusion on days 1 and 21 . Chemotherapy was to be repeated twice at intervals of 3 weeks. This study was reviewed and approved by the review boards of all eleven institutions. Patients were entered into this study according to the following eligibility criteria: (1) histologically proved squamous cell carcinoma of the thoracic esophagus, (2) tumor invasion into and beyond the submucosal layer $\left(\geq \mathrm{T} 1 \mathrm{~b}^{6}\right.$ ), (3) age younger than 75 years, and (4) normal clinical laboratory profile (white blood count $\geq$ $4000 / \mathrm{mm}^{3}$, hemoglobin value $\geq 10 \mathrm{gm} / \mathrm{dl}$, platelet count $\geq$ $100,000 / \mathrm{mm}^{3}$, aspartate aminotransferase and alanine aminotransferase less than twice normal, creatinine $\leq 1.2$ $\mathrm{mg} / \mathrm{dl}$, creatinine clearance $\geq 60 \mathrm{ml} / \mathrm{min}$, blood urea nitrogen $\leq 25 \mathrm{mg} / \mathrm{dl}$, arterial oxygen tension $\geq 70 \mathrm{~mm} \mathrm{Hg}$, and vital capacity $\geq 1500 \mathrm{ml}$ ). Informed consent was obtained from all patients before treatment. Eligible patients were stratified depending on the presence of pathologic lymph node metastasis, the most important prognostic factor.

The second course of chemotherapy was halted if the white blood count fell to less than $2000 / \mathrm{mm}^{3}$, platelet count fell to less than $50,000 / \mathrm{mm}^{3}$, creatinine concentration rose to greater than $1.5 \mathrm{mg} / \mathrm{dl}$, creatinine clearance fell to less than $40 \mathrm{ml} / \mathrm{min}$, or if blood urea nitrogen rose to more than $25 \mathrm{mg} / \mathrm{dl}$. The dose of cisplatin was decreased by $50 \%$ in cases in which creatinine concentration was between 1.2 and $1.5 \mathrm{mg} / \mathrm{dl}$ or creatinine clearance was between 40 and $60 \mathrm{ml} / \mathrm{min}$. The dose of vindesine was decreased by $50 \%$ in cases in which the white blood count was between 2000 and $4000 / \mathrm{mm}^{3}$ or the platelet count between 50,000 and $100,000 / \mathrm{mm}^{3}$.
The sample size was calculated to detect an increase from $40 \%$ to $60 \%$ in the 5-year survival at a significance level $\alpha=5 \%$ and a power of $80 \%$. Therefore at least 98 patients per treatment group were required. Patient characteristics were examined to identify differences between any two groups by means of the $\chi^{2}$ test. Side effects after postoperative treatment were classified according to the JCOG toxicity criteria. ${ }^{7}$ Prognosis was evaluated 44 months after the end of case entry. Survival analysis was performed by means of the Kaplan-Meier method. Survival curves were compared by means of the log rank and generalized Wilcoxon tests. The relative risk was estimated by Cox's regression model. Cancer recurrence was identified locally in the cervical lymph nodes, the mediastinal lymph nodes, the abdominal lymph nodes, the lung, liver, bone, or kidney. The distribution of the sites of recurrence was compared between the two groups by means of the $\chi^{2}$ test. All calculations were performed with SAS software (SAS Institute, Inc., Cary, N.C.) on a UNIX computer in the Statistics Center of the JCOG. Clinicopathologic parameters were characterized according to the TNM classification of the International Union Against Cancer (UICC). ${ }^{6}$

\section{Results}

From December 10, 1988, to July 10, 1991, 205 patients were entered into this study (100 in group A and 105 in group B). They comprised 23.5\% (205/ 872) of all of the patients with esophageal cancer undergoing resection at the involved institutions during the study period. No statistically significant differences were observed in the male/female ratio or the age distribution between the groups (Table I). In group B, 17 patients were not able to complete the postoperative chemotherapy course. Of these patients, 14 underwent only one course of chemotherapy because of side effects or patient refusal of further treatment. Three patients were not able to undergo chemotherapy, two owing to relapse of postoperative pneumonia and one owing to liver dysfunction. No statistically significant differences were present between the two groups with respect to the location of the tumor or pT, pN, pM, and p stage classification (Table II).

Grade 3 side effects were manifest by decreased hemoglobin level $(n=2)$, decreased white blood count $(n=11)$, nausea/vomiting $(n=13)$, diarrhea $(n=1)$, elevated serum creatinine concentration $(n=5)$, or infection $(n=1)$. Grade 4 side effects were manifest by decreased white blood count $(n=$ $2)$, diarrhea $(n=1)$, or elevated serum creatinine concentration $(n=3)$.

The median follow-up period was 59.2 months (range 42.8 to 74.8 months). No significant difference in survival was observed between the two 
groups ( $\log$ rank test, $p=0.55$; Wilcoxon test, $p=$ 0.60 ) (Fig. 1). The 5-year survivals were $45.1 \%$ (95\% confidence interval [CI], 35.2\% to $55.1 \%$ ) in group A and $48.3 \%$ (95\% CI, 38.2\% to $58.3 \%$ ) in group B. The relative risk estimate of group B against group A was 0.89 (95\% CI, 0.61 to 1.31), and it was 0.84 ( $95 \% \mathrm{CI}, 0.57$ to 1.24 ) after adjustment of potentially confounding factors such as sex, age, location, $\mathrm{pT}, \mathrm{pN}$, and $\mathrm{pM}$. In the subgroups with negative nodes ( $\mathrm{pN} 0$ ), the 5-year survivals were $72.4 \%(95 \%$ CI, $54.9 \%$ to $89.9 \%$ ) in group A and $60.3 \%$ (95\% CI, $42.0 \%$ to $78.6 \%$ ) in group B. No significant difference was observed between the two groups (log rank test, $p=0.26$; Wilcoxon test, $p=0.20$ ). The relative risk was 1.71 (95\% CI, 0.66 to 4.42 ). In group A, no patients died within 1 year of the operation. In group B, six patients died within 1 year of the operation. Four of these were not cancerrelated deaths (pneumonia, $n=1$; ileus, $n=1$; traffic accident, $n=1$; and suicide, $n=1$ ).

In the subgroups with positive nodes ( $\mathrm{pN} 1$ ), the 5-year survivals were $35.5 \%(95 \% \mathrm{CI}, 24.2 \%$ to $46.6 \%)$ in group $\mathrm{A}$ and $43.7 \%(95 \% \mathrm{CI}, 31.8 \%$ to $55.6 \%$ ) in group B. No significant difference was noted between the two groups (log rank test, $p=$ 0.15 ; Wilcoxon test, $p=0.13$ ). The relative risk was 0.74 (95\% CI, 0.44 to 1.13 ). In the $\mathrm{pN} 1$ subgroups, survival was analyzed on the basis of the number of positive nodes. In the patients with three or fewer positive nodes (pN1a), the 5-year survivals were $49.8 \%$ (95\% CI, $34.7 \%$ to $64.9 \%)$ in group A $(n=$ $45)$ and $60.6 \%(95 \% \mathrm{CI}, 45.1 \%$ to $76.0 \%)$ in group B $(n=43)$. No significant difference was noted between the two groups (log rank test, $p=0.22$; Wilcoxon test, $p=0.17$ ). The relative risk was 0.67 ( $95 \% \mathrm{CI}, 0.35$ to 1.28 ). In the patients with four or more positive nodes ( $\mathrm{pN} 1 \mathrm{~b}, \mathrm{pN} 1 \mathrm{c})$, the 5-year survivals were $13.8 \%$ (95\% CI, $1.3 \%$ to $26.3 \%$ ) in group $\mathrm{A}(n=29)$ and $21.2 \%(95 \% \mathrm{CI}, 5.2 \%$ to $37.2 \%)$ in group $\mathrm{B}(n=34)$. No significant difference was observed between the two groups ( $\log$ rank test, $p=$ 0.21 ; Wilcoxon test, $p=0.32$ ). The relative risk was 0.71 ( $95 \% \mathrm{CI}, 0.40$ to 1.23 ). No significant difference was noted between the two groups with respect to the site of cancer recurrence (Table III).

\section{Discussion}

The current state of the art of esophageal cancer surgery in Japan includes extensive lymphadenectomy including a three-field dissection. Reported 5-year survivals for patients undergoing a three-field lymphadenectomy (neck, mediastinum, and abdo-
Table II. TNM classification of eligible patients

\begin{tabular}{|c|c|c|c|}
\hline TNM classification & $\begin{array}{c}\text { Group A: } \\
\text { Surgery alone }\end{array}$ & $\begin{array}{c}\text { Group } B: \\
\text { Surgery }+C T\end{array}$ & $\chi^{2}$ Test \\
\hline \multicolumn{4}{|l|}{ Location of tumor } \\
\hline Upper & 8 & 7 & $p=0.86$ \\
\hline Middle & 59 & 60 & \\
\hline Lower & 33 & 38 & \\
\hline \multicolumn{4}{|l|}{ pT } \\
\hline $\mathrm{T} 1$ & 21 & 27 & $p=0.30$ \\
\hline $\mathrm{T} 2$ & 16 & 11 & \\
\hline $\mathrm{T} 3$ & 56 & 64 & \\
\hline $\mathrm{T} 4$ & 7 & 3 & \\
\hline \multicolumn{4}{|l|}{$\mathrm{pN}$} \\
\hline NO & 26 & 28 & $p=0.91$ \\
\hline N1 & 74 & 77 & \\
\hline \multicolumn{4}{|l|}{$\mathrm{pM}$} \\
\hline M0 & 95 & 93 & $p=0.10$ \\
\hline M1 LYM & 5 & 12 & \\
\hline \multicolumn{4}{|l|}{ p Stage } \\
\hline Stage I & 10 & 12 & $p=0.55$ \\
\hline Stage IIA & 16 & 16 & \\
\hline Stage IIB & 23 & 21 & \\
\hline Stage III & 46 & 44 & \\
\hline Stage IV & 5 & 12 & \\
\hline
\end{tabular}

$C T$, Chemotherapy; $L Y M$, lymph nodes.

men) have been as high as $50 \% .^{8}$ Even though a three-field dissection improves survival, ${ }^{9,}{ }^{10}$ its application is limited by the ability of the patient to tolerate the surgical stress. Therefore the development of effective multimodality treatment is urgently required.

Since 1978, the JEOG has been developing adjuvant therapy for esophageal cancer using prospective, randomized, controlled trials. The second phase III study (1981 to 1984) revealed that the 5 -year survival in the postoperative irradiation group was significantly higher than that in the preoperative plus postoperative irradiation group. ${ }^{1}$ The third phase III study (1984 to 1987) was designed to compare postoperative irradiation ( $50 \mathrm{~Gy}$ ) and postoperative combination chemotherapy with cisplatin and vindesine. This study revealed no significant difference in survival between the two groups. Although these results suggest that chemotherapy had an effect on survival equivalent to postoperative irradiation, the results could also have been interpreted as demonstrating that neither postoperative chemotherapy nor irradiation had an impact on survival when compared with surgery alone. Even though the postoperative irradiation regimens in the second and third studies were the same, the 5-year survival in the postoperative irradiation group in the third study $(44 \%)$ was better than that 


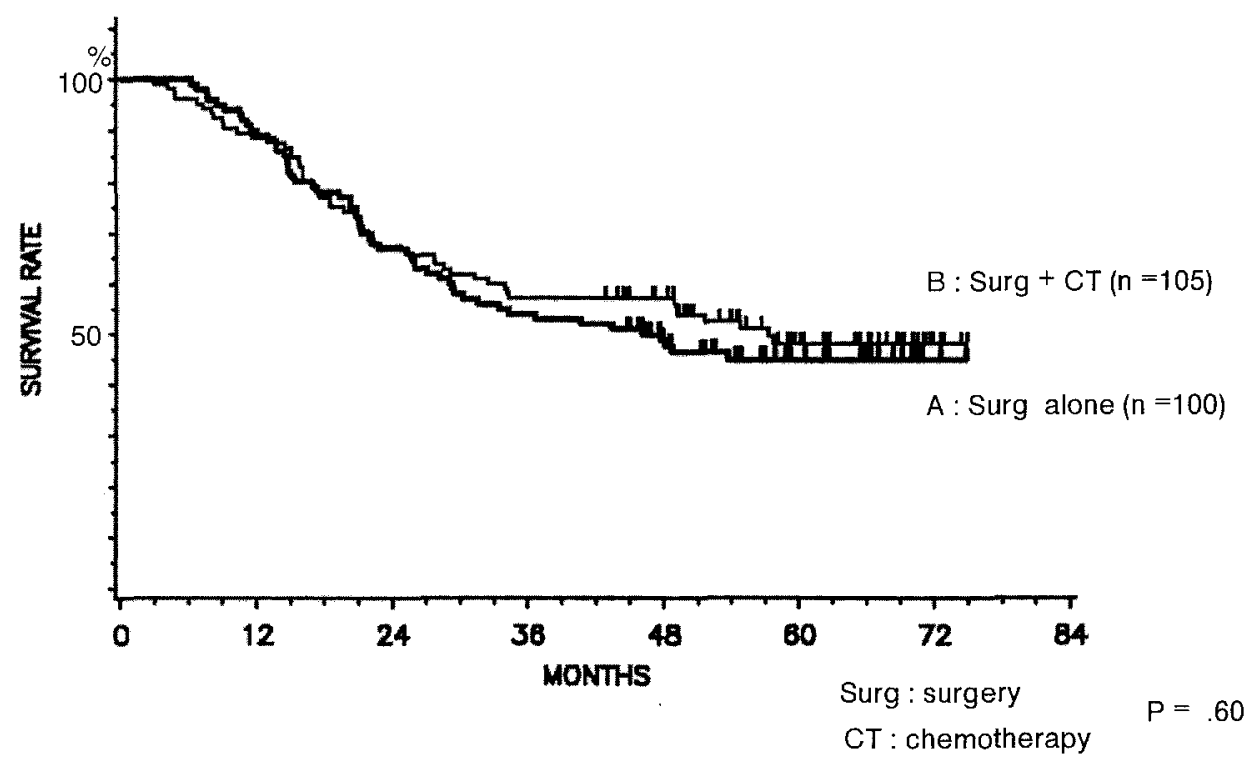

Fig. 1. Survival curves for patients randomized to receive surgery plus chemotherapy or surgery alone, showing no significant difference between treatment groups.

Table III. Site of cancer recurrence

\begin{tabular}{lcc} 
Site of recurrence & $\begin{array}{c}\text { Group A: } \\
\text { Surgery alone }\end{array}$ & $\begin{array}{c}\text { Group } B: \\
\text { Surgery }+C T\end{array}$ \\
\hline Local & 3 & 0 \\
Cervical lymph nodes & 11 & 10 \\
Mediastinal lymph nodes & 9 & 12 \\
Abdominal lymph nodes & 7 & 8 \\
Lung & 7 & 9 \\
Liver & 7 & 5 \\
Others & 13 & 11 \\
\hline
\end{tabular}

CT, Chemotherapy.

in the second study (33\%). This difference may be explained by improvements in the dissection of the cervical-upper mediastinal nodes.

After the surgical improvements, it again became important to study whether adjuvant chemotherapy after optimal surgical treatment had any additional impact on survival. The fourth phase III study (1988 to 1991) was thus designed to compare surgery alone with surgery plus postoperative combination chemotherapy with cisplatin and vindesine. This is the same postoperative chemotherapy regimen used in the third phase III study. The JEOG phase II study of cisplatin and vindesine for patients with advanced esophageal cancer suggested that the chemotherapy used in this study had only a modest effect. In this phase II study, radiographic or endoscopic evidence of a reduction in tumor size by $50 \%$ or more was seen in $16 \%{ }^{11}$ of patients $(5 / 31)$. Although the chemotherapy doses were low by Western standards, only one treatment-related death occurred in the postoperative chemotherapy group in the third phase III study. Therefore the chemotherapy dose was consistent with general policies in Japan.

No statistically significant differences were found in survival between the surgery alone and surgery plus postoperative chemotherapy groups, even with lymph node stratification. In the $\mathrm{pN} 0$ subgroups, the survival in group B was lower than that in group A because no early deaths occurred in group A (within 1 year of the operation). On the other hand, six early deaths (within 1 year) occurred in group B (four of which were not cancer-related). It is unknown whether these deaths were attributed to the postoperative chemotherapy. Recently, the number of positive nodes has been identified as a prognostic factor in esophageal cancer. ${ }^{3,12}$ Even though the pN1 subgroup was divided into $\mathrm{pN} 1 \mathrm{a}$ and $\mathrm{pN} 1 \mathrm{~b}$ depending on the number of positive nodes, the differences in survival between groups $\mathrm{A}$ and $\mathrm{B}$ were not significant in any subgroups.

On the basis of these data, we concluded that postoperative adjuvant chemotherapy with the use of a combination of cisplatin and vindesine has no additive effect on survival in patients with esophageal cancer compared with surgery alone. The present standard for chemotherapy in esophageal 
cancer is a combination of cisplatin and 5-fluorouracil. ${ }^{13}$ In the JEOG phase II study of cisplatin and 5-fluorouracil in patients with advanced esophageal cancer, radiographic or endoscopic evidence of a reduction in tumor size by $50 \%$ or more was seen in $36 \%{ }^{14}$ of patients (14/39). Therefore a prospective, randomized, controlled trial comparing surgery alone with postoperative adjuvant chemotherapy using cisplatin and 5-fluorouracil is in the case entry phase.

\section{REFERENCES}

1. Iizuka $T$, Kakegawa $T$, Ide $\mathrm{H}$, et al. Preoperative radioactive therapy for esophageal carcinoma: randomized evaluation trial in eight institutions. Chest 1988;93:1054 8.

2. Japan Esophageal Oncology Group. A comparison of chemotherapy and radiotherapy as adjuvant treatment to surgery for esophageal carcinoma. Chest 1993;104:203-7.

3. Matsubara T, Ueda M, Yanagida O, Nakaajima T, Nishi M. How extensive should lymph node dissection be for cancer of the thoracic esophagus? J Thorac Cardiovasc Surg 1994;107: 1073-8.

4. Roth JA, Pass HI, Flanagan MM, Graeber GM, Rosenberg JC, Steinberg S. Randomized clinical trial of preoperative and postoperative adjuvant chemotherapy with cisplatin, vindesine, and bleomycin for carcinoma of the esophagus. J Thorac Cardiovasc Surg 1988;96:242-8.

5. Kelsen DP, Minsky B, Smith M, et al. Preoperative therapy for esophageal cancer: a randomized comparison of chemotherapy versus radiation therapy. J Clin Oncol 1990;8:135261.
6. Hermanek P, Henson DE, Huttier RVP, et al, editors. TNM Supplement 1993. Berlin: Springer-Verlag, 1993:119-20.

7. Tobinai K, Kohno A, Shimada Y, et al. Toxicity grading criteria of the Japan Clinical Oncology Group. Jpn J Clin Oncol 1993;23:250-7.

8. Akiyama H, Tsurumaru M, Udagawa H, Kajiyama Y. Radical lymph node dissection for cancer of the thoracic esophagus. Ann Surg 1994;220:364-72.

9. Baba M, Aikou T, Yoshinaka $\mathrm{H}$, et al. Long-term results of subtotal esophagectomy with three-field lymphadenectomy for carcinoma of the thoracic esophagus. Ann Surg 1994;219: 310-6.

10. Fujita $H$, Kakegawa $T$, Yamana $H$, et al. Mortality and morbidity rates, postoperative course, quality of life, and prognosis after extended radical lymphadenectomy for esophageal cancer: comparison of three-field lymphadenectomy with two-field lymphadenectomy. Ann Surg 1995;222: 654-62.

11. Iizuka T, Kakegawa T, Ide H, et al. Phase II evaluation of cisplatin and vindesine in advanced squamous cell carcinoma of the esophagus: Japan Esophageal Oncology Group Trial. Jpn J Clin Oncol 1991;21:176-9.

12. Roder JD, Busch R, Stein HJ, Fink U, Siewert JR. Ratio of invaded to removal lymph nodes as a predictor of survival in squamous cell carcinoma of the esophagus. Br J Surg 1994; 81:410-3.

13. Ajani JA, Ryan B, Rich T, et al. Prolonged chemotherapy for localized squamous carcinoma of the esophagus. Eur $\mathbf{J}$ Cancer 1992;28A:880-4.

14. Iizuka T, Kakegawa T, Ide $H$, et al. Phase II evaluation of cisplatin and 5-Fluorouracil in advanced squamous cell carcinoma of the esophagus: Japan Esophageal Oncology Group Trial. Jpn J Clin Oncol 1992;22:172-6. 